\title{
Role of omega-3 fatty acid supplementation with indomethacin in suppression of disease activity in rheumatoid arthritis
}

\author{
Ashoke Bijoy Das Gupta ${ }^{1}$, A.K.M. Mosharrof Hossain ${ }^{1}$, Md. Hilalul Islam², \\ Sudhangshu Ranjan Dey ${ }^{3}$ and Md. Abdul Latif Khan ${ }^{1}$ \\ Department of ${ }^{1}$ Pharmacology, ${ }^{2}$ Physical Medicine and ${ }^{3}$ Cardiology, Sylhet M.A.G. Osmani Medical \\ College, Sylhet 3100, Bangladesh.e-mail: ahmosharrof@hotmail.com
}

\begin{abstract}
A study was conducted to see the disease activity suppression role of omega-3 fatty acids with indomethacin in patients with rheumatoid arthritis. One group received indomethacin (75 mg) only daily while another group received indomethacin (75 mg) along with omega-3 fatty acids (3 g) daily for 12 weeks. The main outcome measures were DAS 2-28 joints score, number of swollen joints, number of tender joints, duration of morning stiffness, grip strength, pain VAS, patients global VAS, erythrocyte sedimentation rate and C-reactive protein. In terms of outcome both the groups experienced a modest improvement in disease activity after 12 weeks of treatment. However, compared to indomethacin-treated group, omega-3 plus indomethacin-treated group achieved a better improvement in terms of reducing disease activity. Physical functioning, physical role, bodily pain, general health, vitality, social functioning, grip strength, duration of morning stiffness improved significantly better in the combination group compared to indomethacin only group. The safety measures included liver and kidney function tests done didn't differ between the study groups. This study suggests that omega-3 fatty acid supplementation with indomethacin might ameliorate disease activity and be non-steroidal anti-inflammatory drugs (NSAIDs) sparing in rheumatoid arthritis.
\end{abstract}

\section{Introduction}

Rheumatoid arthritis is a systemic autoimmune disease of unknown etiology affect principally the joints, producing a non-suppurative, proliferative and inflammatory synovitis often progresses to destruction of the articular cartilage and ankylosis of the joints leading to crippling deformities ${ }^{1}$.

There are several options for treating the diseases and accordingly the prescribing practices of rheumatologists vary considerably. But over the last few years there has been a significant shift to early use of disease-modifying anti-rheumatic drugs (DMARDs) ${ }^{2}$. Many of these DMARDs decrease disease activity, maintain or improve physical function and retard radiographic joint damage $^{3}$, although patients and physicians are not satisfied with the long-term results of traditional therapy. Research is in progress towards finding a group of new and more effective drugs. Reappraisal of treatment with earlier drugs such as corticosteroids ${ }^{4}$, either alone or in combination with other drugs ${ }^{5}$, is also being continued. Results of intervention with dietary modifications are on the way forward ${ }^{6}$.
A search for the characteristics of diets appropriate for the treatment of rheumatoid arthritis for the patients seeking advice to improve their health by dietary means with or without conventional medication is deemed essential.

It is intriguing for rheumatologists to note that $\alpha$ linolenic acid-rich diet in secondary prevention of coronary heart disease was reported to reduce the recurrence of new cardiac events ${ }^{7}$. The pathogenesis of atheromatosis involves inflammatory processes $^{7,8}$, with obvious similarities to those of rheumatoid synovitis ${ }^{6}$. In the atherosclerotic plaque micro-environment, as in synovitis, macrophages are the principal inflammatory mediators with the ability to form numerous growth factors and cytokines $^{6}$. Nutritional support, in the form of lipids and antioxidants, may act at the foci of modulation of cytokine biology by nutrients and, amino acid provision may alter the availability of substrate for the production of proteins and peptides which are important in the inflammatory process ${ }^{9}$.

A new arena for omega-3 fatty acids has emerged as an adjuvant to drug therapy leading to synergism or decreasing the side-effects of non-steroidal anti- 
inflammatory drugs (NSAIDs) ${ }^{10}$. The potential anti-inflammatory effects of omega-3 fatty acids were suggested by previous studies ${ }^{11-18}$. These researchers found that omega-3 fatty acids may be used to decrease the daily intake of NSAIDs. They used diclofenac ${ }^{13,18}$, naproxen ${ }^{17}$ as supplementation to omega-3 fatty acid.

To our knowledge no study on omega-3 administered with indomethacin in management of the rheumatoid arthritis patients has yet been conducted.

The data generated from the study might be helpful for formulating a better disease management protocol for rheumatoid arthritis patients. The findings of the study might serve as baseline data for further research leading to formulation of new concepts and principles for management of disease in the cost-effective way and might focus attention of the medical professionals about the use of omega-3 fatty acid supplementation in patients with rheumatoid arthritis.

\section{Materials and Methods}

The cases of rheumatoid arthritis attending at the outpatient unit of the Department of Physical Medicine were taken as the study population.

The inclusion criteria for the patients were: rheumatoid arthritis according to 1987 ACR revised criteria, disease duration of $>6$ months, disease activity score from 28 joints (DAS 28 score) had to be 3.2 or more indicating active disease $^{19}$. Patients suffering from other medical diseases including metabolic, endocrine, hepatic, renal, hematological, pulmonary, cardiovascular or any other diseases or conditions that demanded active medical attention were excluded from the study.

The selected 100 patients were equally distributed into two groups using a random allocation procedure. One group $(\mathrm{n}=50)$ received $25 \mathrm{mg}$ indomethacin capsule (Essential Drug Company Limited, Bangladesh) daily for 12 weeks. Another group $(\mathrm{n}=50$ ) received $25 \mathrm{mg}$ indomethacin capsule plus $3 \mathrm{~g}$ omega-3 fatty acids (capsule Meg-3, Ocean Nutrition, Canada) daily for 12 weeks. Clinical assessment of disease activity was done by efficacy variables as: i) disease activity score for rheumatoid arthritis or DAS 28 and HAQ; ii) swollen joint count (0-28); iii) tender joint count (0-28); iv) duration of morning stiffness (in min); v) grip strength $(\mathrm{mmHg})$; vi) patients' assessment of pain or Pain VAS $(0-10 \mathrm{~cm})$ and vii) erythrocyte sedimentation rate. All the study parameters were estimated before initiation of treatment and after 12 weeks of continuous treatment.

Collected data were processed and analyzed using software SPSS for windows, version 11.5. Data presented on categorical scale were compared between groups using $\mathrm{x}^{2}$ probability test. Quantitative data were compared between groups using Student's t-test.

\section{Results}

In course of treatment 9 from indomethacin group and 10 from indomethacin plus omega-3 fatty acid group were dropped out.

The mean age of both the study groups was $49.9 \pm$ 8.2 and $44.7 \pm 7.7$ years respectively. They did not differ in age distribution $(p=0.144)$ and the groups were matched in respect to sex distribution $(p=0.398)$. Duration of disease, BMI and RA tests results were identical in either group $(\mathrm{p}=0.398$; $\mathrm{p}=0.841$ and $\mathrm{p}=0.406$ respectively).

DAS-28, swollen joint count, tender joint count, duration of morning stiffness, grip strength, pain VAS, patients global VAS as well as erythrocyte sedimentation rate, C-reactive protein values before administrations of either indomethacin or indomethacin plus omega-3 fatty acids did not differ, which evidences that base line study indices were matched in between the two study groups ( $>0.05$; Table I). Swollen joint count, tender joint count, morning stiffness also decreased 12 weeks after administration of indomethacin group ( $<<0.001$ ), while grip strength markedly increase.

Pain VAS, patients global VAS, erythrocyte sedimentation rate and C-reactive protein values significantly $(\mathrm{p}<0.001)$ declined in indomethacin only group 12 weeks after administration of drug. In the indomethacin plus omega-3 fatty acid-treated group, DAS-28 substantially $(\mathrm{p}<0.05)$ decreased. Decrease of swollen joint count, tender joint count, morning stiffness were statistically significant $(p<0.001)$ while grip strength tended to increase (Table I).

All recorded values of pain VAS, patients global VAS, erythrocyte sedimentation rate, C-reactive protein markedly increased $(\mathrm{p}<0.001)$ in combination treatment group of indomethacin plus omega-3 fatty acids.

Indomethacin lowered DAS-28 by $34.2 \%$ and indomethacin plus omega- 3 fatty acid lowered by 41.9\% (Table II). Indomethacin plus omega-3 fatty acid lowered DAS-28 indices more than indomethacin administered alone ( $<<0.05)$. Swollen joint count, tender joint count, morning stiffness 
were markedly improved in indomethacin plus omega-3 as compared to indomethacin alone (69.8\% vs $78.2 ; 70.9$ vs 83.8 ; 69.4 vs $78.7 \%$ respect -tively). Increase of grip strength was more marked in combination treatment group (4.24 vs $7.9 \%)$
Pain VAS, erythrocyte sedimentation rate improvement were more marked in combination group compare to indomethacin only, whereas effect on patients global VAS and C-reactive protein changes were also identical (Table II).

Table I: Comparison of disease activity before and after treatment with either indomethacin or indomethacin plus omega-3 fatty acids

\begin{tabular}{l|cccc}
\hline Disease activity score & \multicolumn{2}{|c}{ Indomethacin-treated group } & \multicolumn{2}{c}{ Indomethacin plus omega-3 fatty acid-treated group } \\
\cline { 2 - 5 } & $\begin{array}{c}\text { Before treatment } \\
(\mathrm{n}=50)\end{array}$ & $\begin{array}{c}\text { After treatment } \\
(\mathrm{n}=41)\end{array}$ & $\begin{array}{c}\text { Before treatment } \\
(\mathrm{n}=50)\end{array}$ & $\begin{array}{c}\text { After treatment } \\
(\mathrm{n}=40)\end{array}$ \\
\hline DAS 28 (2-10 joints) & $7.29 \pm 0.39$ & $4.80 \pm 0.55^{*}$ & $7.23 \pm 0.44^{\mathrm{ns}}$ & $4.2 \pm 36 \bullet$ \\
Swollen joints & $14.20 \pm 2.77$ & $4.29 \pm 1.35^{* *}$ & $14.03 \pm 2.90^{\mathrm{ns}}$ & $3.33 \pm 1.79 \bullet \bullet$ \\
Tender joints & $16.83 \pm 2.87$ & $4.90 \pm 2.40^{* *}$ & $15.90 \pm 2.99^{\mathrm{ns}}$ & $2.85 \pm 1.75 \bullet$ \\
\hline Morning stiffness & $150.1 \pm 58.3$ & $45.9 \pm 13.4^{* *}$ & $147.3 \pm 54.1^{\mathrm{ns}}$ & $31.4 \pm 10.8$ \\
\hline Grip strength & $165 \pm 13$ & $172 \pm 13^{*}$ & $163 \pm 11$ & $176 \pm 11$ \\
\hline Pain VAS & $6.75 \pm 1.01$ & $2.52 \pm 0.99^{* *}$ & $6.58 \pm 0.91^{\mathrm{ns}}$ & $1.66 \pm 0.55 \bullet$ \\
Patients global VAS & $66.50 \pm 3.62$ & $32.50 \pm 5.77^{* *}$ & $67.38 \pm 4.24^{\mathrm{ns}}$ & $34.27 \pm 3.80 \bullet \bullet$ \\
Erythrocyte sedimentation rate & $77 \pm 15$ & $42 \pm 13^{* *}$ & $76 \pm 15^{\mathrm{ns}}$ & $31 \pm 08 \cdot \bullet$ \\
C-reactive protein & $42.32 \pm 865$ & $17.8 \pm 2.19^{* *}$ & $4.16 \pm 6.44^{\mathrm{ns}}$ & $15.36 \pm 2.03 \cdot \bullet$ \\
\hline
\end{tabular}

ns=Non-significance of difference between indomethacin only treated group and indomethacin plus omega-3 fatty acid-treated group before administration of drug; *Significance of difference between scores before and after administration of indomethacin at $\mathrm{p}<0.05$; **Significance of difference between scores before and after administration of indomethacin plus omega- 3 at $\mathrm{p}<0.05$

Physical functioning, physical role, bodily pain, general health, vitality, social functioning, emotional role and mental health scores before administration of either indomethacin or indomethacin plus omega-3 fatty acid did not differ (Table III).

Table II: Percentage changes of disease activity in study subjects after treatment

\begin{tabular}{l|cc}
\hline Disease activity score & $\begin{array}{c}\text { Indomethacin } \\
(\mathrm{n}=41)\end{array}$ & $\begin{array}{c}\text { Indomethacin } \\
\text { plus omega-3 } \\
(\mathrm{n}=40)\end{array}$ \\
\hline DAS 28 (2-10 joints) & -34.2 & -41.9 \\
Swollen joints & -69.8 & -78.2 \\
Tender joints & -70.9 & -83.8 \\
Morning stiffness & -69.4 & -78.7 \\
Grip strength & +4.24 & +7.9 \\
Pain VAS & -62.7 & -74.8 \\
\hline Patients global VAS & -51.1 & -49.1 \\
Erythrocyte sedimentation rate & -44.4 & -59.2 \\
\hline C-reactive protein & -57.9 & -61.6 \\
\hline + indicates increase in percentage, - indicates decrease in percentage
\end{tabular}

Baseline SF-36 variables in both the study groups were matched $(p>0.05)$. In the indomethacintreated group, physical functioning significantly increased from $47.5 \pm 6.4$ to $61.6 \pm 7.5(\mathrm{p}<0.01)$. Physical role and bodily pain significantly increased as estimated 12 weeks after treatment (from $28.3 \pm 3.7$ to $64.5 \pm 10.1 ; \mathrm{p}<0.001$ and from $33.4 \pm 3.9$ to $62.0 \pm 4.5 ; \mathrm{p}<0.001$ respectively).

General health, vitality, mental health also improved (Table III). Social functioning and emotional role were same after 12 weeks of treatment $(\mathrm{p}<0.05)$.

In the indomethacin plus omega-3 fatty acid treatment group physical functioning (from $47.7 \pm$ 7.4 to $68.1 \pm 6.8, \mathrm{p}<0.001$ ), physical role (from $28.0 \pm 3.9$ to $74.3 \pm 6.6 ; \mathrm{p}<0.001$ ), bodily pain (from $33.1 \pm 3.5$ to $65.8 \pm 4.5 ; \mathrm{p}<0.001$ ), general health (56.3 \pm 0.7 to $69.7 \pm 2.2 ; \mathrm{p}<0.01)$, vitality $(47.5 \pm 0.6$ to $64.2 \pm 4.0 ; \mathrm{p}<0.001)$, mental health $(66.2 \pm 1.3$ to $79.2 \pm 0.7 ; \quad \mathrm{p}<0.02)$ score substantially increased from base line (on 0 day) 12 weeks after administration of drugs (Table III).

\section{Discussion}

Rheumatoid arthritis is a chronic inflammatory condition the exact cause of which is unknown, though it is believed to be an autoimmune disease. Treatment plays a key role in controlling the inflammation and minimizing joint damage. Treatment usually entails a combination of drug therapy including NSAIDs and disease modifying agents.

NSAIDs are frequently used as symptomatic control of pain, however concern about side effects 
Table III: Comparison of various dimensions of SF-36 before and after treatment with either indomethacin or indomethacin plus omega-3 fatty acids

\begin{tabular}{|c|c|c|c|c|}
\hline \multirow[t]{2}{*}{$S F-36$} & \multicolumn{2}{|c|}{ Indomethacin-treated group } & \multicolumn{2}{|c|}{ Indomethacin plus omega-3 fatty acid-treated group } \\
\hline & $\begin{array}{l}\text { Before treatment } \\
\qquad(n=50)\end{array}$ & $\begin{array}{l}\text { After treatment } \\
\qquad(\mathrm{n}=41)\end{array}$ & $\begin{array}{l}\text { Before treatment } \\
\qquad(n=50)\end{array}$ & $\begin{array}{l}\text { After treatment } \\
\qquad(n=40)\end{array}$ \\
\hline Physical functioning & $47.5 \pm 6.4$ & $61.6 \pm 7.5^{* *}$ & $47.7 \pm 7.4^{\mathrm{ns}}$ & $68.1 \pm 6.8$ \\
\hline Physical role & $28.3 \pm 3.7$ & $64.5 \pm 10.1^{* *}$ & $28.0 \pm 3.9$ & $74.3 \pm 6.6$ \\
\hline Bodily pain & $33.4 \pm 3.9$ & $62.0 \pm 4.5^{* *}$ & $33.1 \pm 3.5$ & $65.8 \pm 4.5$ \\
\hline General health & $56.3 \pm 0.7$ & $68.1 \pm 2.5^{*}$ & $56.3 \pm 0.7$ & $69.7 \pm 2.2$ \\
\hline Vitality & $46.7 \pm 0.67$ & $59.6 \pm 5.7^{*}$ & $47.5 \pm 0.6$ & $64.2 \pm 4.0$ \\
\hline Social functioning & $64.6 \pm 1.7$ & $66.4 \pm 4.7^{\mathrm{ns}}$ & $64.8 \pm 1.8$ & $71.9 \pm 6.4$ \\
\hline Emotional role & $51.0 \pm 1.0$ & $51.5 \pm 1.5^{\mathrm{ns}}$ & $50.9 \pm 1.1$ & $52.7 \pm 0.8$ \\
\hline Mental health & $66.3 \pm 1.4$ & $78.3 \pm 0.9 *$ & $66.2 \pm 1.3$ & $79.2 \pm 0.7$ \\
\hline
\end{tabular}

ns=Non-significance of difference between these two groups before administration of drug; *Significance of difference between scores before and after administration of indomethacin at $\mathrm{p}<0.05$; **Significance of difference between scores before and after administration of indomethacin and omega- 3 at $\mathrm{p}<0.05$

limited their use and the biological agents remains the cornerstone ${ }^{17}$.

In our present study we have carefully selected those patients who did not have any other concomitant diseases or any systemic involvement due to rheumatoid arthritis. NSAIDs yet play a gold standard therapy for the patients with rheumatoid arthritis to relieve pain and reduce the inflammation caused by the disease. We selected indomethacin as the NSAIDs, supply ensured by medical college hospital at conventional doses of $75 \mathrm{mg}$ daily in divided doses keeping it in mind the side effects like gastrointestinal bleeding, fluid retention and NSAIDs induced nephropathy.

The beneficial effects of omega-3 fatty acids in patients with rheumatoid arthritis have been increased interest for its role in suppressing the inflammation. Nutritional supplementation with omega-3 fatty acids may represent an additional therapy to the traditional pharmacological treatment due to the anti-inflammatory properties $^{13-17}$. Omega-3 fatty acids are essential because they are not synthesized in the body and must be obtained through diet or supplementation.

In this study commercial preparation of omega-3 fatty acids containing $1 \mathrm{~g}$ of EPA and DHA (most commercial fish oil capsule contains $180 \mathrm{mg}$ of EPA and $120 \mathrm{mg}$ of DHA) has been used $3 \mathrm{~g}$ daily in divided doses in combination with $75 \mathrm{mg}$ of indomethacin. We used indomethacin with the view that it is cheaper and freely available and thereby contribute to better compliance. Our study differs from others studies in that we used indomethacin instead of diclofenac or other NSAIDs ${ }^{16-17}$.

In this study we observed that indomethacin alone and in combination with omega-3 fatty acids were well-tolerated by all the study population and had a favorable safety profile. There were no clinically notable differences between indomethacin monotherapy and combined therapy with indomethacin and omega-3 fatty acids in respect to the incidence of adverse clinical or laboratory events.

Among the baseline characteristics, age was almost identically distributed between indomethacin and indomethacin in combination with omega-3 fatty acids. Forty percent of the patients being affected in $4^{\text {th }}$ decade of life. No sex difference was evident between groups with male-female ratio being roughly $1: 2$. Although it was not the intention of our study to find the age-sex distribution of rheumatoid arthritis, the findings were almost consistent with those of Jayson and Gernan's study $^{19}$.

Their study demonstrates that women are affected approximately 3-times more often than men. The study also describes that no age group is exempted from the disease and the onset is most common during the $4^{\text {th }}$ and $5^{\text {th }}$ decades of life with $80 \%$ of all patients developing the disease between the ages of $35-50$ years $^{19}$. The study groups were almost homogeneous in terms of mean duration of illness and rheumatoid arthritis positivity (80\% vs. $86 \%$ respectively). Overweight or obesity was almost evenly distributed between groups. Thus all the baseline variables were fairly comparable between indomethacin and indomethacin in combination with omega-3 fatty acid groups meeting statistical prerequisite before the intervention. The groups were demonstrated to be comparable with respect of disease activity and all the dimensions of SF-36 Health Survey at baseline. In the present study we observed that both indomethacin and indomethacin plus omega-3 fatty acid responded significantly to treatment reducing the efficacy variables but response was significantly better in combination 
group. Both the groups experienced a modest improvement in disease activity in terms of almost in all the efficacy variables. However, indomethacin and omega-3 combination group demonstrated a better improvement than indomethacin alone.

Navarro et al. ${ }^{20}$ have shown that supplementation with omega-3 polyunsaturated fatty acids (omega-3 PUFAs) found in fish oils is beneficial for rheumatoid arthritis patients. Kremer $^{13,14}$ has summarized the current knowledge concerning fish oils and rheumatoid arthritis and concluded that the use of 3-6 g of fish oils (omega-3 dietary fatty acids) daily for 12 weeks or more significantly diminished joint pain and morning stiffness in patients $^{13}$. Several studies ${ }^{15,16,17}$ have shown that the improvement in some patients is significant enough to allow them to reduce or discontinue their use of NSAIDs ${ }^{17,21}$.

Other researchers $^{22}$ in an attempt to determine the long-term effects of fish oil supplementation in rheumatoid arthritis patients conducted a year-long, double-blind, randomized study. After 3 months of supplementation the patients on fish oil alone had improved considerably when compared to the other 2 groups; but the improvement became more pronounced after 12 months of supplementation leading to the conclusion that long-term supplementation with fish oils benefits rheumatoid arthritis patients significantly and may lessen their need for NSAIDs and other rheumatoid arthritis medications ${ }^{23}$.

Fortin et al. $^{23}$ from the Harvard Medical School has analyzed the results of these studies. Their metaanalysis covered 10 double-blind, randomized, placebo-controlled studies aimed at determining the effect of fish oil supplementation on 8 measures of arthritis severity including the number of tender joints, number of swollen joints, extent of morning stiffness, grip strength, erythrocyte sedimentation rates, and overall global assessment of disease severity. The studies involved a total of 368 participants who took fish oil supplements for at least three months. The meta-analysis revealed a highly significant decrease in the number of tender joints and a significant shortening in the duration of morning stiffness among patients supplemented with fish oils ${ }^{23}$.

There is considerable evidence ${ }^{13}$ that fish oil supplementation can alleviate the symptoms of rheumatoid arthritis. It is less clear how much of fish oil is required to exert therapeutic effect to eliminate the need for NSAIDs. Researchers at the Albany Medical College found that the fish oil group achieved a significant improvement of their symptoms from the initiation of supplementation and until the substitution of diclofenac with the placebo $^{13}$.

The researchers ${ }^{15-18}$ suggested that some rheumatoid arthritis patients using fish oil supplementation may be able to discontinue NSAIDs without experiencing a flare-up of their disease. They also observed that the benefits achieved from supplementing with 9 g/day of fish oil were not greater than those observed in other studies using only 3 to $6 \mathrm{~g} /$ day $^{13}$. The increasing consumption of omega-3 fatty acids reduces the inflammatory mediators of rheumatoid arthritis and, consequently, allows some patients to reduce or discontinue use of NSAIDs ${ }^{15,17,21 .}$

Several study ${ }^{20,24,25}$ suggest that the level of $\alpha$ linolenic acid was lower in the synovial fluid of rheumatoid arthritis patients, but not in their plasma. The level of DHA (a major component of fish oil) also tended to be lower in synovial fluids of rheumatoid arthritis patients, but not in their plasma. The researchers ${ }^{20}$ conclude that rheumatoid arthritis patients have an abnormal fatty acid profile and a significant deficiency in certain essential fatty acids that is omega-3 fatty acid. The mechanism of the anti-inflammatory and analgesic properties of omega-3 fatty acid might be their ability to inhibit cytokine production and inflammatory mediators at cellular and tissue concentration ${ }^{24,25}$.

All these evidences and the findings derived from our study suggest that NSAIDs yet play an important role in treating patients with rheumatoid arthritis. Daily supplementation of fish oil can be as an NSAID-sparing agent in patient with rheumatoid arthritis.

\section{References}

1. Rosenberg AE. Bones, joints, and soft tissue tumor. In: Robbins and Cotran Pathologic basis of disease. Kumar V, Abbas AK, Fausto N (eds). $7^{\text {th }}$ ed. Philadelphia, Elsevier Saunders, 2005, pp 1273-1324.

2. Conaghan PG, Crotty M, Oh ES, Day RO, Brooks PM. Antirheumatic drug prescribing behavior of Australasian Rheumatologists 1984-94. $\mathrm{Br} \quad \mathrm{J}$ Rheumatol.1997; 36; 487-90.

3. Edmonds JP, Scott DI, Frust DE, Brooks P. Paulus HE. Antirheumatic drugs: A proposed new classification. Arthritis Rheum. 1993; 36: 336-39.

4. Kirwan JR. The effect of glucocorticoids on joint destruction in rheumatoid arthritis. $\mathrm{N}$ Engl $\mathrm{J}$ Med. 1995; 333: 142-46.

5. Tugwell P, Boers M. Long acting drug combinations in rheumatoid arthritis: Updated overview. In: Rheumatoid arthritis: Pathogenesis, assessment, 
outcome and treatment. Wolfe F, Pincus T, (eds). New York, 1994, 357-71.

6. Skoldstam L. Hagfor L, Johansson G. An experimental study of a Mediterian diet intervention for patients with rheumatoid arthritis. Ann Rheum Dis. 2003; 62: 20814.

7. De Lorgeril M, Renaud S, Mamelle N, Salen P, Martin J L, Monjaud I, Guidallet J, Touboul P, Delaye J. Mediterranean alpha-linolenic acid rich diet in secondary prevention of coronary heart disease. Lancet 1994; 343: 1454-59.

8. Ross R. The pathogenesis of atherosclerosis: A perspective for the 1990s. Nature 1993; 362: 801-09.

9. Grimble RF. Nutritional modulation of cytokine biology. Nutrition 1998; 14: 634-40.

10. Ariza-Ariza R, Mestanza-Peralta M, Cardiel MH. Omega-3 fatty acids in rheumatoid arthritis: An overview. Semin Arthtis Rheum. 1998; 27: 366-70.

11. James MJ, Cleland LG. Dietary n-3 fatty acids therapy for rheumatoid arthritis. Semin Arthritis Rheum. 1997; 27: 85-97.

12. Lau CS, Morley KD, Belch JJ. Effects of fish oil supplementation on non-steroidal anti-inflammatory drug requirements in patients with mild rheumatoid arthritis: A double-blind placebo controlled study. Br J Rheum. 1993; 32: 982-89.

13. Kremer JM, Lawrence DA, Petrillo GF, Litts LL, Mullaly PM, Reynes RI, Stocker RP, Parhami N, Greenstein NS, Fuchs BR, et al. Effects of high-dose fish oil on rheumatoid arthritis after stopping nonsteroidal anti-inflammatory drugs: Clinical and immune correlates. Arthritis Rheum. 1995; 38: 110714.

14. Kremer JM. Omega-3 fatty acid supplements in rheumatoid arthritis. Am J Clin Nutr. 2000; 71 (suppl): 349S-51S.

15. Belch JJF, Ansell D, Madhok R, O’Dowd A, Sturrok RD. Effects of altering dietary essential fatty acid on requirements for non-steroidal anti-inflammatory drugs in patients with rheumatoid arthritis: A double-blind placebo controlled study. Annals Rheum Dis. 1988; 47: 96-104.

16. Kjelsen-Kragh J, Lund JA, Riise T, Finnanger B, Haaland K, Finstad R, Mikkelsen K, Forre O. Dietary omega-3 fatty acid supplementation and naproxen treatment in patient with rheumatoid arthritis. Rheumatology 1992; 19: 1531-36.

17. Galarraga B, Ho M, Youssef HM, Hill A, McMahon H, Hall C, Ogston S, Nuki G, Belch JJF. Cod liver oil (omega-3 fatty acid) as a non-steroidal antiinflammatory drug sparing agent in rheumatoid arthritis. Rheumatology 2008; 47: 665-69.

18. Van Riel PLCM, Van Gestel AM. Clinical outcome measures in rheumatoid arthritis. Ann Rheum Dis. 2000; 59 (Suppl 1): i28-i31.

19. Jayson MIV, Gernan DM. Clinical features of rheumatoid arthritis. In: Oxford textbook of medicine. Weatherall DJ, Ledingham JGG, Warrell DA (eds). $2^{\text {nd }}$ ed. Oxford, ELBS, 1987, pp 3-8.

20. Navarro E. Abnormal fatty acid pattern in rheumatoid arthritis: A rationale for treatment with marine and botanical lipids. J Rheumatol. 2000; 27: 298-303.

21. Geusens P, Wouters C, Nijs J, Jiang Y, Dequeker. Long-term effect of omega-3 fatty acid supplementation in active rheumatoid arthritis: A 12-month, double-blind, controlled study. Arthritis Rheum. 1994; 37: 824-29.

22. Piet G. Long-term effect of omega-3 fatty acid supplementation in active rheumatoid arthritis. Arthritis Rheum. 1994; 37: 824-29.

23. Fortin PR, Lew RA, Liang MH, Wright CA, Beckett LA Chalmers TC, Sperling RI. Validation of a metaanalysis: The effects of fish oil in rheumatoid arthritis. J Clin Epidemiol. 1995; 48: 1379-90.

24. Philip CC. Omega-3 polyunsaturated fatty acid, inflammation and inflammatory diseases. Am J Clin Nutr. 2006; 83: S1505-19.

25. Yashodhara BM, Umakanth S, Pappachan JM, Bhat SK, Choo BH. Omega-3 fatty acid: A comprehensive review of their role in health and disease. Postgrad Med J. 2009; 85: 84-90. 